\title{
Indicação de genótipos polinizadores para os cultivares de macieira SCS425 Luiza e SCS427 Elenise
}

Thyana Lays Brancher ${ }^{1}$, Maraisa Crestani Hawerroth², Marcus Vinícius Kvitschal ${ }^{3}$, Filipe Schmidt Schuh4 ${ }^{4}$ Karoline Cardoso de Vargas ${ }^{5}$, Frederico Denardi ${ }^{3}$ e Altamir Frederico Guidolin ${ }^{6}$

Resumo-A macieira apresenta autoincompatibilidade gametofítica e, por isso, faz-se necessário eleger genótipos polinizadores eficientes para cada cultivar copa. Nesse sentido, o objetivo deste trabalho foi selecionar genótipos polinizadores para as macieiras SCS425 Luiza e SCS427 Elenise a partir da genotipagem dos alelos de autoincompatibilidade S, via marcadores de DNA, associada à realização de cruzamentos testes a campo. Nos ciclos de 2014/15 e 2017/18, as polinizações a campo foram conduzidas em delineamento de blocos ao acaso, com quatro repetições, constituídas por 25 inflorescências de duas flores cada. Foram utilizados conjuntos de primers específicos para identificação de 16 alelos $S$, via PCR. Todos os genótipos testados podem ser indicados como possíveis polinizadores, respectivamente, para 'SCS425 Luiza' $\left(S_{5} S_{9}\right): 135 / 114\left(S_{3} S_{19}\right), 135 / 140\left(S_{3} S_{?}\right)$, SCS433 Felix $3\left(S_{3} S_{26}\right)$ - compatíveis; e SCS431 Felix $1\left(S_{4} S_{5}\right)$ e SCS426 Venice $\left(S_{3} S_{9}\right)$ - semicompatíveis; e para 'SCS427 Elenise' $\left(S_{3} S_{23}\right)$ : SCS431 Felix $1\left(S_{4} S_{5}\right)$, e SCS436 Felix $6\left(S_{5} S_{\text {? }}\right)$ - compatíveis; e SCS433 Felix $3\left(S_{3} S_{26}\right)$ e SCS435 Felix $5\left(S_{3} S_{4}\right)$ - semicompatíveis.

Termos para indexação: Malus x domestica Borkh.; autoincompatibilidade gametofítica; polinização artificial; alelos $S$; marcadores de DNA.

\section{Recommendation of pollinizers for the apple varieties SCS425 Luiza and SCS427 Elenise}

Abstract - The apple tree presents gametophytic self-incompatibility, for this it is necessary to choose efficient pollinizers for each scion cultivar. Thus, the objective of this work was to select pollinizers for the cultivars SCS425 Luiza and SCS427 Elenise by genotyping the $S$-alleles of self-incompatibility using DNA markers, associated with the performance of test crosses in the field. In the seasons $2014 / 15$ and $2017 / 18$, the field artificial pollination tests were conducted in a randomized block design, with four replications of 25 inflorescences of two flowers each. The identification of S-alleles was performed via PCR using specific sets of primers for $16 \mathrm{~S}$-alleles. All genotypes tested can be indicated as possible field pollinizers for 'SCS425 Luiza' $\left(S_{5} S_{9}\right)$, being $135 / 114\left(S_{3} S_{19}\right), 135 / 140\left(S_{3} S_{?}\right)$, SCS433 Felix $3\left(S_{3} S_{26}\right)$ compatible; SCS431 Felix $1\left(S_{4} S_{5}\right)$, SCS426 Venice $\left(S_{3} S_{9}\right)$ semi-compatible; and for 'SCS427 Elenise' $\left(S_{3} S_{23}\right)$, being SCS431 Felix $1\left(S_{4} S_{5}\right)$, SCS436 Felix $6\left(S_{5} S_{7}\right)$ compatible; a SCS433 Felix $3\left(S_{3} S_{26}\right)$, SCS435 Felix $5\left(\mathrm{~S}_{3} \mathrm{~S}_{4}\right)$ semi-compatible.

Index terms: Malus x domestica Borkh.; gametophytic self-incompatibility; artificial pollination; alleles S; DNA markers.

\section{Introdução}

Embora apresente flores hermafroditas, a maioria dos cultivares (cvs.) de macieira necessita de polinização cruzada para que haja a fertilização das flores e formação de frutos. Isso ocorre em função da autoincompatibilidade gametofítica presente no gênero Malus, cujo mecanismo é governado pelo locus multialélico "S" (RAMALHO, 2012). Quando os genitores possuem os mesmos alelos $S$ no grão de pólen e no pistilo, ocorre a paralisação do crescimento do tubo polínico emitido pelos grãos de pólen. Logo, a fecundação ou a ocorrência de autofecundação são improváveis. Já na presença de um único alelo $S$ diferente ocorrerá a semicompatibilidade, onde apenas o pólen portador do alelo $S$ diferente é viável para polinização e, quando todos os alelos $S$ são diferentes em relação aos alelos $S$ do estigma, há a possibilidade de formação de $100 \%$ das sementes potenciais e maior probabilidade de adequada formação dos frutos (YAMANE \& TAO, 2009; RAMALHO, 2012; MATSUMOTO, 2014).

A quantidade de frutos bem formados, o número de sementes por fruto e sua distribuição nos carpelos são parâmetros importantes para definir a compatibilidade genética entre genótipos de macieira (DENARDI \& STUKER, 2008; KVITSCHAL et al., 2013).

Recebido em 20/12/2020. Aceito para publicação em 11/1/2021.

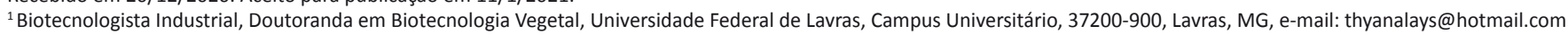

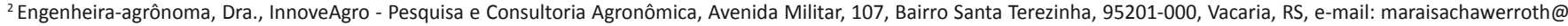
gmail.com

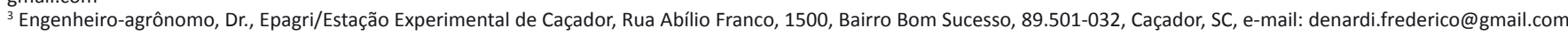
(aposentado), marcusvinicius@epagri.sc.gov.br

${ }^{4}$ Engenheiro-agrônomo, Dr., SENAR - Serviço nacional de aprendizagem rural, Rua Carlos Coelho de Souza, 210, DER, 89506-030, Caçador, SC, e-mail: filipess_@hotmail.com

${ }^{5}$ Engenheira-agrônoma, Vargas Agrowork, Linha Canalle, Castelhano, 89514-899, Caçador, SC, e-mail: karol@conection.com.br

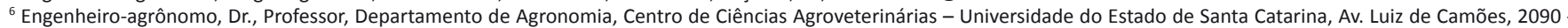

Conta Dinheiro, 88520-000, Lages, SC, e-mail: altamir.guidolin@udesc.br 
Por essas razões, os pomares comerciais de macieira são compostos pelos cvs. copa produtores de frutos e por um ou mais genótipos polinizadores, podendo estes serem ou não produtores de frutos comerciais. Além de serem geneticamente compatíveis, o cv. copa e o(s) respectivo(s) genótipo(s) polinizador(es) deve(m) apresentar coincidência quanto às épocas de floração, exigências edafoclimáticas e reação semelhante às doenças para facilitar o manejo do pomar (ALBUQUERQUE JUNIOR et al., 2011; KVITSCHAL et al., 2013; MATSUMOTO, 2014). A caracterização do locus $S$ via uso de marcadores moleculares permite a identificação prévia de potenciais genótipos polinizadores quanto à compatibilidade genética com os cvs. copa (ALBUQUERQUE JUNIOR et al., 2011; HALÁSZ et al., 2011; MATSUMOTO, 2014). Além de poder ser realizada a qualquer momento, essa técnica é rápida e eficiente e não sofre interferência ambiental, comuns aos experimentos teste conduzidos a campo.

'SCS425 Luiza' foi lançado pela Epagri a fim de disponibilizar à cadeia produtiva um cv. de macieira com colheita precoce - 02/fevereiro - e resistente à mancha foliar de Glomerella (Colletotrichum gloeosporioides). Produz frutos com ótima qualidade visual, bom sabor e boa textura de polpa, com capacidade de conservação similar à 'Galaxy' quando colhidos no mesmo estágio de maturação (DENARDI et al., 2019a).

Já 'SCS427 Elenise' é resistente à mancha foliar de Glomerella, produz frutos de maturação tardia - colheita a partir de 25/abril - e tem alta capacidade de frigoconservação. A textura de polpa de seus frutos é equivalente à de 'Cripps Pink', porém tem sabor menos ácido e mais doce (DENARDI et al., 2020).

O objetivo deste trabalho foi selecionar genótipos polinizadores compatíveis para os cvs. de macieira SCS425 Luiza e SCS427 Elenise a partir da genotipagem dos alelos $S$ via PCR, associada à realização de cruzamentos teste a campo.

\section{Material e métodos}

Os genótipos polinizadores testados neste trabalho foram definidos a partir de dados históricos de fenologia (Figura 1), buscando garantir a coincidência dos períodos de floração destes com os cvs. copa analisados, associado à adequada produção e germinação de pólen (germinação in vitro $>40 \%$ ).

Para a polinização de 'SCS425 Luiza' foram testadas as seleções 135/114 e $135 / 140$ e os cvs. SCS426 Venice, SCS431 Felix 1 e SCS433 Felix 3. Para o 'SCS427 Elenise' foram utilizados os cvs. SCS431 Felix 1, SCS433 Felix 3, SCS435 Felix 5 e SCS436 Felix 6.

Todos os genótipos candidatos a polinizadores foram desenvolvidos pela Epagri, sendo que 'SCS426 Venice' produz frutos de alto valor comercial e é resultado do cruzamento entre 'Imperatriz' e 'Baronesa' (DENARDI et al., 2019b). Os cvs. da série Felix são resultantes de pomar de 'Imperatriz' conduzido sob polinização aberta, com a presença dos cvs. silvestres Malus eley, Malus baccata e Golden Gem. Já as seleções do cruzamento 135 são resultantes de sementes de polinização aberta de 'Imperatriz' colhidas em pomar experimental contendo diversos outros cvs., incluindo cvs. silvestres que eram utilizados como polinizadores na área (genitor masculino desconhecido).

Os cruzamentos-testes a campo do ciclo 2014/2015 foram realizados em Caçador, SC, na Estação Experimental de Caçador (Epagri/EECd), município situado a $26^{\circ} 50^{\prime} 11,753^{\prime \prime}$ S $50^{\circ} 58^{\prime} 32,102^{\prime \prime}$ O; Altitude: $960 \mathrm{~m}$. No ciclo 2017/2018, essa ação foi repetida em Fraiburgo, SC, a $27^{\circ} 3^{\prime} 32,09^{\prime \prime} \mathrm{S} 50^{\circ} 54^{\prime} 21,856^{\prime \prime}$ O; Altitude: $1.050 \mathrm{~m}$.

O experimento fatorial foi composto pelos fatores de tratamento 'genótipo polinizador' e 'ciclo de avaliação'. O delineamento experimental foi em blocos ao acaso, com quatro repetições compostas por 25 inflorescências cada, mantendo-se apenas duas flores por inflorescência em estádio de balão rosado.

As flores foram emasculadas e polinizadas manualmente, com subsequente proteção das inflorescências com papel kraft por ao menos 72 horas para evitar contaminações com pólen exógeno. O tratamento controle consistiu da emasculação das flores e proteção com papel kraft, sem a realização da polinização.

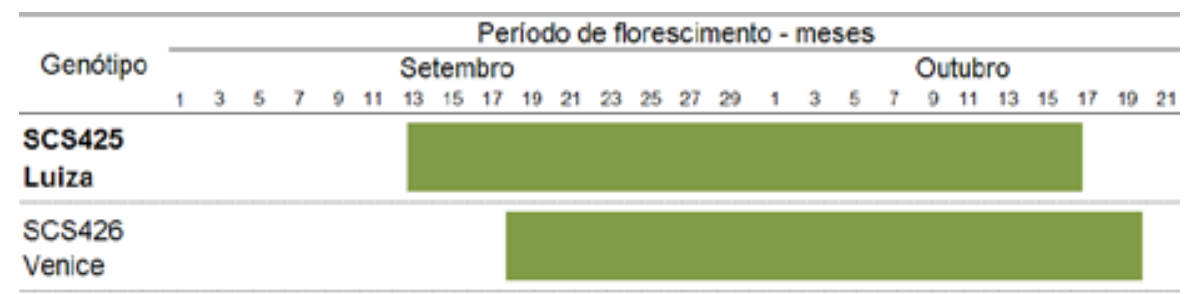

\begin{tabular}{l|l}
\hline $135 / 114$ & \\
\hline $135 / 140$ & 0 \\
\hline
\end{tabular}

\section{$\operatorname{SCS} 431$}

Felix 1

SCS433

Fellix 3

\section{SCS427}

Elenise

\section{SCS435}

Felix 5

$\operatorname{SCS} 436$

Felix 6

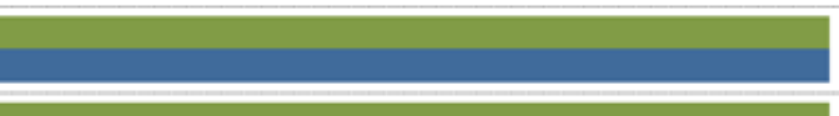

Figura 1. Período de floração dos genótipos de macieira em seis períodos de avaliação (ciclos 2007/2008 a 2013/2014). A cor verde se refere ao 'SCS425 Luiza' e a cor azul se refere ao 'SCS427 Elenise', e respectivos genótipos polinizadores testados

Figure 1. Flowering period of apple tree genotypes observed along six seasons of evaluation (seasons 2007/2008 to 2013/2014). The green color refers to 'SCS425 Luiza' and the blue color refers to 'SCS427 Elenise', and its respective pollinizers tested 
Foram mensurados o número de frutos formados por inflorescência, de sementes por fruto e de sementes verdadeiras por fruto, sendo todas as variáveis expressas em unidade. Foram consideradas como sementes verdadeiras as que possuíam o tegumento íntegro e o endosperma formado. Além disso, no ciclo 2017/18 foi avaliado o número de sementes por lóculo. Os dados foram submetidos à análise de variância e de médias pelo teste Tukey $(p \leq 0,05)$.

Paralelamente aos cruzamentos-tes- tes a campo, os alelos $S$ dos cvs. copa e dos genótipos polinizadores foram identificados via PCR. Folhas jovens e sadias de cada genótipo foram coletadas aleatoriamente e armazenadas a $-20^{\circ} \mathrm{C}$ até o momento da utilização. A extração de DNA e a determinação dos respectivos alelos $S$ foram realizadas conforme Brancher et al. (2020), onde foram testados primers específicos para identificar 16 alelos $S$ de macieira (Tabela 1 ).

Para auxiliar na determinação da presença de cada alelo $S$, além da comparação com o tamanho dos respectivos fragmentos (Tabela 1), foram utilizados como padrão os cvs. Fuji $\left(S_{1}\right.$ e $S_{g}$; GenBank no D50837 e D50836, respectivamente), Golden Delicious $\left(\mathrm{S}_{2} \mathrm{e}\right.$ $S_{3}$; U12199 e U12200, respectivamente), Gloster ( $S_{4} ; \mathrm{AF327223),} \mathrm{Gala}\left(S_{5}\right.$; U19791), Marubakaido $\left[\begin{array}{lll}S_{6} & \text { e } & S_{26}\end{array}\right.$; (AGAPITO-TENFEN et al., 2015)], Idared $\left(S_{7} ; \mathrm{AB032246)}\right)$ Mclntosh $\left(S_{10}\right.$; AB052683), Delicious $\left(S_{19} ; A B 035273\right)$, Alkmene $\left(S_{22} ;\right.$ AF327222), Mutsu $\left(S_{20} ; \mathrm{AB019184}\right)$, Granny Smith $\left(S_{23}\right.$;

Tabela 1. Sequência dos primers e temperatura de anelamento na PCR para a identificação de alelos $S$ em macieira e digestão por enzimas de restrição

Table 1. Primers sequences and annealing temperature for PCR to identify the S-alleles of apple tree and restriction enzymes digestion

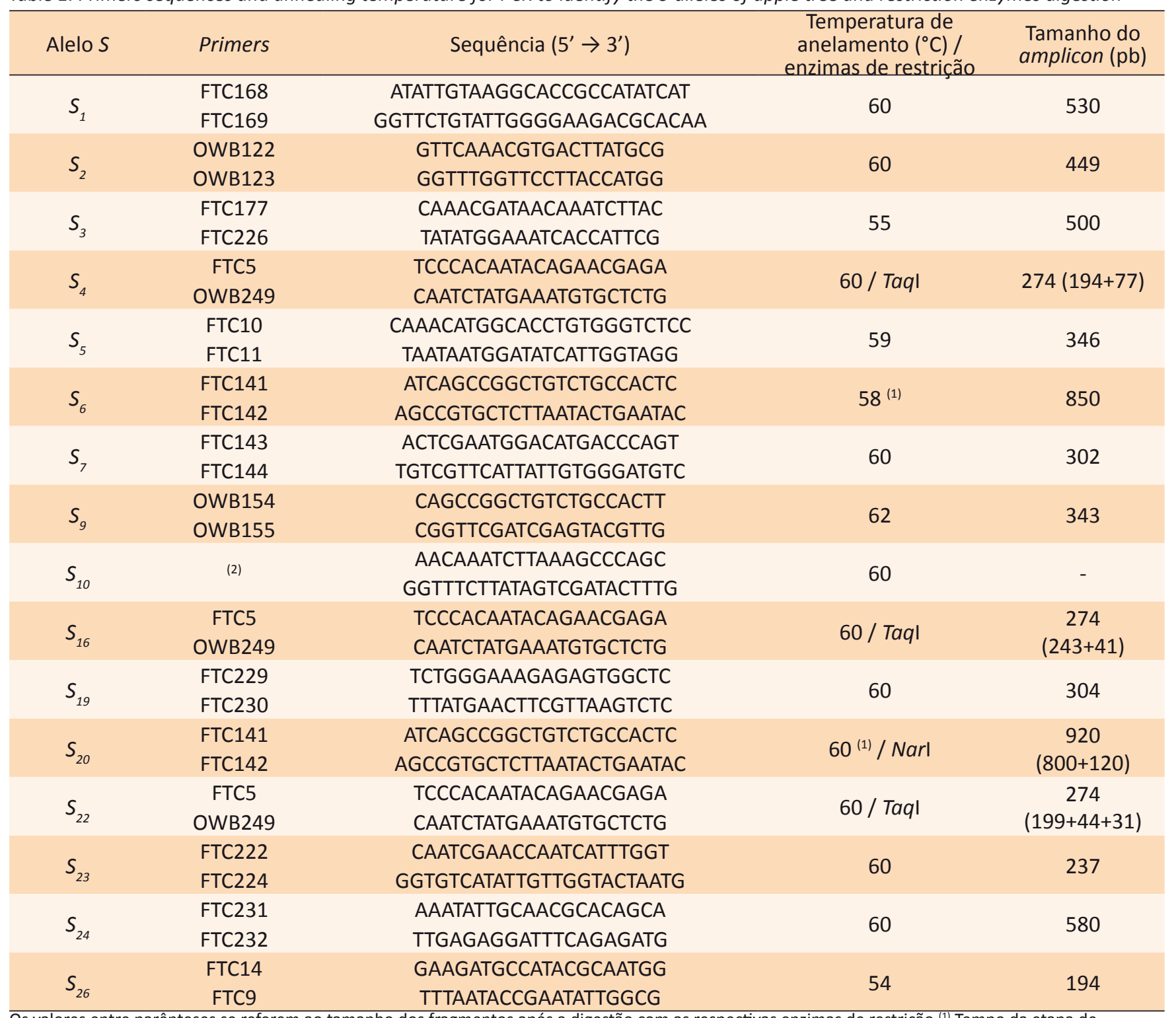

Os valores entre parênteses se referem ao tamanho dos fragmentos após a digestão com as respectivas enzimas de restrição. ${ }^{(1)}$ Tempo da etapa de extensão de $45 \mathrm{seg}$. (2) Primer proposto por Kitahara \& Matsumoto (2002). Condições de reação: 3 min à $94^{\circ} \mathrm{C}$, seguido por 30 ciclos à $94^{\circ} \mathrm{C}$ por 1 min, $60^{\circ} \mathrm{C}$ por $1 \mathrm{~min} \mathrm{e} 72^{\circ} \mathrm{C}$ por $1 \mathrm{~min}$, com etapa de extensão final à $72^{\circ} \mathrm{C}$ por $10 \mathrm{~min}$, mantendo à $4^{\circ} \mathrm{C}$ depois da conclusão da amplificação. Tamanho do amplificado de $282 \mathrm{pb}$ para o alelo $S_{10}$ e depois do tratamento com a enzima Narl gera dois fragmentos: 185 e $97 \mathrm{pb}$. 
AF239809), e Braeburn ( $S_{24}$; AF016920). Não se utilizou padrão para o alelo $S_{16}$ (AF016919), uma vez que nenhum genótipo sabidamente portador desse alelo $S$ é mantido no Banco de Germoplasma de Macieira da Epagri.

Os produtos da PCR foram analisados por eletroforese em gel de agarose $3 \%$, utilizando marcador de peso molecular de 50pb. As amostras foram coradas com o intercalante fluorescente GelRed $^{\text {'m. }}$. O perfil de amplificação dos alelos $S$ foi analisado por imagem capturada em fotodocumentador Kodak Gel Logic 212 Pro. Os alelos $S$ foram considerados presentes quando os fragmentos foram coincidentes com o tamanho indicado na literatura e com os fragmentos dos cvs. padrão para cada alelo $S$.

Para confirmar que os frutos formados nos cruzamentos testes foram resultantes de cada combinação entre cvs. copa e os polinizadores, dez seedlings de cada cruzamento foram coletados aleatoriamente e tiveram seus alelos $S$ identificados.

\section{Resultados e discussão}

Não houve formação de frutos no tratamento controle nos testes conduzidos a campo, para ambos os cvs. copa. O cv. SCS425 Luiza sofreu efeito da interação entre genótipo polinizador e ciclo de avaliação para o número de frutos formados por inflorescência. Já o número de sementes por fruto variou em função do ano de avaliação.

A interação entre genótipo polinizador e o ciclo de avaliação foi significativa para número de frutos formados por inflorescência, número de sementes por fruto e número de sementes verdadeiras por fruto para 'SCS427 Elenise'. Em ambos os cvs. copa, os fatores testados não exerceram efeito sobre o número de sementes por lóculo. Essa resposta é de grande relevância, uma vez que frutos com formato simétrico e desenvolvimento normal são, entre outros fatores, decorrentes da formação de ao menos uma semente em cada um dos cinco carpelos que normalmente formam as flores no gênero Malus (DENARDI \& STUKER, 2008).

'SCS426 Venice' e 'SCS433 Felix 3' proporcionaram o maior número médio de frutos formados no ciclo 2017/2018 no 'SCS425 Luiza' (1,23 e 1,27, respectivamente). Contudo, no ciclo 2014/2015 os genótipos polinizadores testados não influenciaram este caráter, sendo que todos proporcionaram a formação de mais de um fruto por inflorescência (Tabela 2). Já o número de sementes por fruto nas maçãs 'SCS425 Luiza' foi maior no ciclo $2014 / 15$, não havendo diferença entre os genótipos polinizadores testados. Em média, foram observadas 5,13 sementes verdadeiras por fruto nos cruzamentos conduzidos no ciclo 2017/18.

Ao analisar o desempenho de frutos formados por inflorescência do 'SCS427 Elenise' no ciclo 2014/15, houve ao me- nos um fruto nos diferentes cruzamentos dirigidos. Contudo, no ciclo 2017/18, nem todas as inflorescências polinizadas apresentaram formação de frutos (média menor que um fruto por inflorescência). 0 polinizador SCS435 Felix 5 se destacou por possibilitar a formação regular de frutos por inflorescência nos dois ciclos avaliados (Tabela 2). No ciclo 2014/2015 verificou-se maior número de sementes por fruto em relação ao ciclo 2017/18, contudo, foi observado em ambos os ciclos grande proporção de sementes verdadeiras. O 'SCS431 Felix 1', no ciclo $2017 / 18$, proporcionou o menor número de frutos por inflorescência e menor número de sementes nos frutos de 'SCS427 Elenise'.

Tabela 2. Desempenho dos cultivares SCS425 Luiza e SCS427 Elenise quanto ao número de frutos formados por inflorescência, número de sementes por fruto e número de sementes verdadeiras por fruto obtidos via testes de polinização controlada, realizados nos ciclos 2014/2015 e 2017/20018

Table 2. Performance of cultivars SCS425 Luiza and SCS427 Elenise for number of fruits formed per inflorescence, number of seeds per fruit and number of true seeds per fruit, obtained via controlled pollination tests performed in the 2014/2015 and 2017/20018 seasons

\begin{tabular}{|c|c|c|c|c|c|c|}
\hline \multicolumn{7}{|c|}{ SCS425 Luiza } \\
\hline \multirow[t]{2}{*}{$\begin{array}{c}\text { Genótipo } \\
\text { polinizadora }\end{array}$} & \multicolumn{2}{|c|}{$\begin{array}{l}\text { Frutos por } \\
\text { inflorescência }\end{array}$} & \multicolumn{2}{|c|}{$\begin{array}{l}\text { Sementes por } \\
\text { fruto } \\
\text { (média) }\end{array}$} & \multicolumn{2}{|c|}{$\begin{array}{c}\text { Sementes } \\
\text { verdadeiras por } \\
\text { fruto (média) }\end{array}$} \\
\hline & $2014 / 15$ & $2017 / 18$ & $2014 / 15$ & $2017 / 18$ & $2014 / 15$ & 2017/18 \\
\hline $135 / 114$ & 1,33 Aa & $0,97 \mathrm{Bb}$ & 7,01 & 6,23 & 5,56 & 5,83 \\
\hline $135 / 140$ & $1,40 \mathrm{Aa}$ & $0,82 \mathrm{Bb}$ & 6,18 & 5,31 & 4,37 & 4,97 \\
\hline SCS426 Venice & $1,37 \mathrm{Aa}$ & $1,23 \mathrm{Aa}$ & 5,79 & 5,81 & 4,73 & 5,37 \\
\hline SCS431 Felix 1 & $1,32 \mathrm{Aa}$ & $0,68 \mathrm{Bb}$ & 6,28 & 5,16 & 4,93 & 4,87 \\
\hline SCS433 Felix 3 & $1,21 \mathrm{Aa}$ & $1,27 \mathrm{Aa}$ & 7,06 & 6,07 & 5,71 & 4,91 \\
\hline Média & 1,33 & 0,99 & $6,47 \mathrm{~A}$ & $5,72 B$ & 5,06 & 5,19 \\
\hline \multicolumn{7}{|c|}{ SCS427 Elenise } \\
\hline \multirow[t]{2}{*}{$\begin{array}{l}\text { Genótipo } \\
\text { polinizador }\end{array}$} & \multicolumn{2}{|c|}{$\begin{array}{l}\text { Frutos por } \\
\text { inflorescência }\end{array}$} & \multicolumn{2}{|c|}{$\begin{array}{l}\text { Sementes por } \\
\text { fruto } \\
\text { (média) }\end{array}$} & \multicolumn{2}{|c|}{$\begin{array}{l}\text { Sementes } \\
\text { verdadeiras por } \\
\text { fruto (média) }\end{array}$} \\
\hline & $2014 / 15$ & $2017 / 18$ & $2014 / 15$ & $2017 / 18$ & $2014 / 15$ & $2017 / 18$ \\
\hline SCS431 Felix 1 & 1,33Aa & $0,27 \mathrm{Bb}$ & $7,13 \mathrm{Aa}$ & $1,45 \mathrm{Bb}$ & $6,29 \mathrm{Aa}$ & $1,40 \mathrm{Bb}$ \\
\hline SCS433 Felix 3 & $1,23 \mathrm{Aa}$ & 0,70Ba & $6,81 \mathrm{Aa}$ & 3,78Ba & $6,18 \mathrm{Aa}$ & 3,61Ba \\
\hline SCS435 Felix 5 & $1,09 A a$ & $0,81 \mathrm{Aa}$ & $6,53 \mathrm{Aa}$ & $4,68 \mathrm{Ba}$ & $5,51 \mathrm{Aa}$ & 4,51Aa \\
\hline SCS436 Felix 6 & $1,40 \mathrm{Aa}$ & $0,86 \mathrm{Ba}$ & $7,12 \mathrm{Aa}$ & $4,06 \mathrm{Ba}$ & $6,44 \mathrm{Aa}$ & 3,93Ba \\
\hline Média & 1.26 & 0.66 & 6.90 & 3.49 & 6.11 & 3.36 \\
\hline
\end{tabular}


Os cvs. copa e os genótipos polinizadores necessitam ser geneticamente compatíveis, pois o crescimento do tubo polínico é inibido quando $o$ alelo $S$ presente na célula haploide do grão de pólen é igual a um dos alelos $S$ expressos no pistilo da flor polinizada (MATSUMOTO, 2014). A análise molecular se mostrou eficiente na genotipagem dos alelos $S$, tendo como base o padrão de bandas formado em comparação aos respectivos fragmentos esperados para cada alelos $S$ (Tabela 3).

Foi possível identificar os alelos $S_{3}$ e $S_{9}$ no 'SCS426 Venice', corroborando com Brancher et al. (2021). As seleções 135/114 e 135/140 são descendentes do cv. Imperatriz $\left(S_{3} S_{5}\right)$ via polinização aberta, e em ambas foi identificado o alelo $S_{3}$, herdado desse genitor. Na seleção 135/114 foi identificado o alelo $S_{19}$. Contudo, com o conjunto de iniciadores testados, não foi possível identificar o segundo alelo $S$ da '135/140'. Já, no 'SCS433 Felix 3' e no 'SCS435 Felix 5' foi identificado o $S_{3}$ herdado do genitor feminino 'Imperatriz'. O $S_{4}$ foi o segundo alelo identificado no 'SCS435 Felix 5' e o $S_{26}$ foi identificado no 'SCS433 Felix 3'. O 'SCS436 Felix 6' e o 'SCS431 Felix 1 ' foram genotipados como $S_{5} S_{\text {? }}$ e $S_{4} S_{5}$, respectivamente. Vale destacar que o alelo $S_{4}$ identificado no 'SCS431 Felix 1 ' e no 'SCS435 Felix 5', faz parte de um conjunto de alelos raros, normalmente encontrado em cvs. antigos e silvestres (BROOTHAERTS et al., 2004).

Nos genótipos cujo segundo alelo $S$ não foi identificado pelos iniciadores testados, esse foi considerado como um alelo diferente daqueles identificados no cv. copa. Ao identificar nos genótipos polinizadores um alelo igual a um dos alelos do cv. copa, definiu-se a relação como semicompatibilidade. Logo, para o 'SCS425 Luiza', três genótipos se mostraram completamente compatíveis: '135/114', '135/140' e 'SCS433 Felix 3'; e dois semicompatíveis: 'SCS431 Felix 1 ' e 'SCS426 Venice'. Já para o 'SCS427 Elenise', dois genótipos foram caracterizados como compatíveis: 'SCS436 Felix 6' e 'SCS431 Felix 1'; e dois semicompatíveis: 'SCS435 Felix 5' e 'SCS433 Felix 3' (Tabela 3).

Teoricamente, a formação de frutos e sementes seria maior entre genótipos completamente compatíveis, porém essa diferença não foi identificada na
Tabela 3. Alelos S dos genótipos polinizadores, compatibilidade com a 'SCS425 Luiza' e 'SCS427 Elenise', respectivamente, possíveis genótipos segregantes a partir do cruzamento com as cvs. copa, e número de seedlings de cada locus $\mathrm{S}$ entre 10 indivíduos escolhidos aleatoriamente por cruzamento

Table 3. S-alleles of pollinizers, compatibility with 'SCS425 Luiza' and 'SCS427 Elenise', respectively, possible segregant genotypes from the cross with the canopy, and number of seedlings that have each S-locus genotyped among the 10 individuals random chosen per crossing

\begin{tabular}{|c|c|c|c|c|}
\hline $\begin{array}{l}\text { Genótipo } \\
\text { polinizador }\end{array}$ & Locus S & $\begin{array}{c}\text { Compatibilidade } \\
\text { com SCS425 } \\
\text { Luiza }\left(S_{5} S_{9}\right)\end{array}$ & $\begin{array}{l}\text { Possíveis genótipos } \\
\text { dos seedlings } \\
\text { originados dos } \\
\text { cruzamentos com } \\
\text { SCS425 Luiza }\end{array}$ & $\begin{array}{l}\text { Número } \\
\text { de } \\
\text { seedlings }\end{array}$ \\
\hline \multirow{5}{*}{$135 / 114$} & \multirow{5}{*}{$S_{3} S_{19}$} & \multirow{5}{*}{ Compatível } & $\mathrm{S}_{3} \mathrm{~S}_{5}$ & 2 \\
\hline & & & $S_{3} S_{9}$ & 1 \\
\hline & & & $S_{5} S_{19}$ & 2 \\
\hline & & & $S_{9} S_{19}$ & 2 \\
\hline & & & $S_{3} S_{19}^{* *}$ & 3 \\
\hline \multirow{4}{*}{$135 / 140$} & \multirow{4}{*}{$S_{3} S_{?}$} & \multirow{4}{*}{ Compatível } & $S_{3} S_{5}$ & 1 \\
\hline & & & $S_{3} S_{9}$ & 4 \\
\hline & & & $S_{5} S_{?}$ & 3 \\
\hline & & & $S_{9} S_{?}$ & 2 \\
\hline \multirow{2}{*}{ SCS431 Felix 1} & \multirow{2}{*}{$S_{4} S_{5}$} & \multirow{2}{*}{ Semicompatível } & $S_{4} S_{5}$ & 8 \\
\hline & & & $\mathrm{S}_{4} \mathrm{~S}_{9}$ & 2 \\
\hline \multirow{4}{*}{ SCS433 Felix 3} & \multirow{4}{*}{$S_{3} S_{26}$} & \multirow{4}{*}{ Compatível } & $S_{3} S_{5}$ & 0 \\
\hline & & & $S_{3} S_{9}$ & 3 \\
\hline & & & $S_{5} S_{?}$ & 2 \\
\hline & & & $S_{9} S_{?}$ & 5 \\
\hline \multirow{3}{*}{ SCS426 Venice } & \multirow{3}{*}{$\mathrm{S}_{3} \mathrm{~S}_{9}$} & \multirow{3}{*}{ Semicompatível } & $S_{3} S_{5}$ & 3 \\
\hline & & & $S_{3} S_{9}$ & 5 \\
\hline & & & $S_{5} S_{9}^{* *}$ & 2 \\
\hline $\begin{array}{l}\text { Genótipo } \\
\text { polinizador }\end{array}$ & Locus S & $\begin{array}{c}\text { Compatibilidade } \\
\text { com SCS427 } \\
\text { Elenise }\left(S_{3} S_{23}\right)\end{array}$ & $\begin{array}{l}\text { Possíveis genótipos } \\
\text { dos seedlings } \\
\text { originados dos } \\
\text { cruzamentos com } \\
\text { SCS427 Elenise }\end{array}$ & $\begin{array}{l}\text { Número } \\
\text { de } \\
\text { seedlings }\end{array}$ \\
\hline \multirow{5}{*}{ SCS431 Felix 1} & \multirow{5}{*}{$\mathrm{S}_{4} \mathrm{~S}_{5}$} & \multirow{5}{*}{ Compatível } & $\mathrm{S}_{3} \mathrm{~S}_{4}$ & 2 \\
\hline & & & $S_{3} S_{5}$ & 2 \\
\hline & & & $\mathrm{S}_{4} \mathrm{~S}_{23}$ & 3 \\
\hline & & & $S_{5} S_{23}$ & 2 \\
\hline & & & $S_{3} S_{5} S_{23}{ }^{* *}$ & 1 \\
\hline \multirow{2}{*}{ SCS433 Felix 3} & \multirow{2}{*}{$S_{3} S_{26}$} & \multirow{2}{*}{ Semicompatível } & $S_{3} S_{?}$ & 5 \\
\hline & & & $S_{23} S_{?}$ & 5 \\
\hline \multirow{2}{*}{ SCS435 Felix 5} & \multirow{2}{*}{$\mathrm{S}_{3} \mathrm{~S}_{4}$} & \multirow{2}{*}{ Semicompatível } & $S_{3} S_{4}$ & 3 \\
\hline & & & $S_{4} S_{23}$ & 7 \\
\hline \multirow{4}{*}{ SCS436 Felix 6} & \multirow{4}{*}{$S_{5} S_{?}$} & \multirow{4}{*}{ Compatível } & $S_{3} S_{5}$ & 2 \\
\hline & & & $S_{3} S_{?}$ & 2 \\
\hline & & & $S_{5} S_{23}$ & 4 \\
\hline & & & $\mathrm{S}_{23} \mathrm{~S}_{2}$ & 2 \\
\hline
\end{tabular}

**Genótipos adversos aos esperados para os respectivos cruzamentos.

$\mathrm{S}$, representa um alelo não identificado, sendo considerado diferente de qualquer alelo identificado nesta avaliação. 
'SCS427 Elenise'. Do mesmo modo, no ciclo 2017/18, a formação de frutos da 'SCS425 Luiza' via polinização semicompativel com 'SCS426 Venice' proporcionou o mesmo número de frutos quando cruzada com 'SCS433 Felix 3 (totalmente compatível), não havendo diferença no número de sementes formadas, somente entre os ciclos de avaliação.

Esse resultado corrobora com Schneider et al. (2005) e Heo et al. (2012), os quais não constataram diferença quanto à frutificação e ao número de sementes por fruto em cruzamentos compatíveis e semicompatíveis via polinização artificial. Porém, Schneider et al. (2005) verificaram que, quando é levado em conta o comportamento dos cvs. submetidos à polinização aberta em condições de cultivo, há maior formação de frutos e sementes por fruto em cruzamentos compatíveis do que em cruzamentos entre genótipos semicompatíveis.

Logo, é provável que a alta quantidade de pólen depositada sobre os estigmas no processo de polinização artificial compense a ocorrência da semicompatibilidade, permitindo a formação de frutos e número de sementes similares aos verificados entre genótipos compatíveis. Além disso, existem casos em que combinações de genótipos específicos compatíveis podem resultar em menor produção de frutos devido a características morfológicas dos órgãos reprodutores vegetais e ao ambiente (SAPIR et al., 2008). Logo, a seleção dos melhores polinizadores deve levar em consideração conjuntamente a genotipagem do locus $S$ e os resultados da realização dos testes de polinização artificial a campo.

Em casos de combinações semicompatíveis, o cuidado a ser tomado é a adequada proporção de plantas copa em relação a plantas polinizadoras, associada à densidade de insetos polinizadores, a fim de garantir adequada disponibilidade de pólen e eficiente polinização. Vale destacar a combinação 'SCS425 Luiza' e 'SCS426 Venice'. Ambos apresentam frutos de padrão comercial, boa frutificação e liberação de pólen, e são uma boa alternativa para compor pomares comerciais conjuntamente dispostos. Contudo, a eficiente polinização promovida pelos insetos, principalmente pelas abelhas, é de grande importância no sentido de compensar a semi- compatibilidade entre esses dois cvs.

Considerando a genotipagem dos 50 seedlings tomados ao acaso provenientes de frutos de 'SCS425 Luiza' $\left(S_{5} S_{9}\right)$ a partir dos cruzamentos-testes, cinco apresentaram genótipos diferentes do esperado. Contudo, apresentaram ao menos um dos alelos $S$ presentes nos pais (Tabela 3). No cruzamento com a seleção 135/114 $\left(S_{3} S_{19}\right)$, foram identificadas três plantas $S_{3} S_{19}$ ou seja: os dois alelos do genitor masculino. No cruzamento com 'SCS426 Venice' $\left(\mathrm{S}_{3} \mathrm{~S}_{9}\right)$, foram identificadas duas plantas $S_{5} S_{9}$. Ambos os casos podem ser resultantes de falhas no mecanismo de autoincompatibilidade (LI et al., 2016).

Nos 50 seedlings resultantes dos cruzamentos envolvendo o 'SCS427 Elenise', foi identificada apenas uma exceção aos genótipos esperados: no cruzamento com 'SCS431 Felix 1' foi identificado o genótipo triploide $S_{3} S_{5} S_{23}$. A triploidia pode ocorrer naturalmente em cruzamentos do gênero Malus, mesmo que sejam casos raros (BROWN, 2012), onde, normalmente, a planta herda os dois alelos $S$ do óvulo (neste caso: $S_{3}$ e $S_{23}$ do 'SCS427 Elenise' e o $S_{5}$ do 'SCS431 Felix 1'.

\section{Conclusões}

Com base nos cruzamentos testes feitos a campo e na compatibilidade genética, todos os genótipos polinizadores testados podem ser indicados para polinização eficiente a campo dos cvs. 'SCS425 Luiza' e 'SCS427 Elenise'.

\section{Agradecimentos}

À Epagri, ao CNPq (Projeto 404475/2016-7), à Capes, à Fapesc, à Udesc e ao Finep, pelo fomento à pesquisa e pelas bolsas de estudo.

\section{Referências}

AGAPITO-TENFEN, S.Z.; DANTAS, A.C. DE M.; DENARDI, F.; NODARI, R.O. Identification of the Er1 resistence gene and RNase S-alleles in Malus prunifolia var. ringo rootstock. Scientia Agricola, v. 72, n. 1, p. 62-68, 2015. DOI: https://doi.org/10.1590/0103-90162013-0210.

ALBUQUERQUE JUNIOR, C.L. DE; DENARDI, F.; DE DANTAS, A.C.M.; NODARI, R.O. The self-incompatible RNase S-alleles of Bra- zilian apple cultivars. Euphytica, v. 181, n. 2, p. 277-284, 2011. DOI: https://doi. org/10.1007/s10681-011-0431-0.

BRANCHER, T.L.; HAWERROTH, M.C.; KVITSCHAL, M.V.; MANENTI, D.C.; GUIDOLIN, A.F. Self-incompatibility alleles in important genotypes for apple breeding in Brazil. Crop Breeding and Applied Biotechnology, v. 20, n. 4, p. 1-9, 2020. DOI: https://doi. org/10.1590/1984-70332020v20n4a54.

BRANCHER, T. L.; HAWERROTH, M.C.; KVITSCHAL, M. V.; GUIDOLIN, A. F.; DENARDI, F.; COUTO, M.; CARLESSO, C. Identification of pollinizers for apple 'SCS426 Venice'. Bragantia, v. 80, e0521, 2021. DOI: https:// doi.org/10.1590/1678-4499.20200129.

BROOTHAERTS, W.; VAN NERUM, I.; KEULEMANS, J. Update on and review of the incompatibility (S-) genotypes of apple cultivars. HortScience, v. 39, n. 5, p. 943-947, 2004. DOI: https://doi.org/10.21273/ hortsci.39.5.943.

BROWN, S. Apple. In: Fruit Breeding. Boston, MA: Springer US, 2012.

DENARDI, F.; KVITSCHAL, M.V.; HAWERROTH, M.C.; ARGENTA, L.C. SCS426 Venice: new apple cultivar with glomerella leaf spot resistance and picking time in march. Crop Breeding and Applied Biotechnology, v. 19, n. 4, p. 481-486, 2019a. DOI: https://doi. org/10.1590/1984-70332019v19n4c69.

DENARDI, F.; KVITSCHAL, M.V.; HAWERROTH, M.C.; ARGENTA, L.C. 'SCS425 Luiza': new apple cultivar with medium chilling requirement and resistant to glomerella leaf spot (Colletotrichum spp.). Revista Brasileira de Fruticultura, v. 41, n. 1, p. e-109, 2019b. DOI: https://doi.org/10.1590/010029452019109.

DENARDI, F.; KVITSCHAL, M.V.; HAWERROTH, M.C.; ARGENTA, L.C. SCS427 Elenise: lateripening apple variety of good storability and resistance to Glomerella Leaf Spot. Agropecuária Catarinense, v. 33, n. 2, p. 32-36, 2020. Disponível em: https://publicacoes. epagri.sc.gov.br/RAC/article/view/537/936. Acesso em: 29 out. 2020.

DENARDI, F.; STUKER, H. Eficiência de diferentes cultivares de macieira como polinizadoras da 'Castel Gala' e da 'Condessa'. Agropecuária Catarinense, v. 21, p. 79-83, 2008.

HALÁSZ, J.; HEGEDUS, A.; GYÖRGY, Z.; PÁLLINGER, É.; TÓTH, M.; HEGEDÛS, A.; GYÖRGY, Z.; PÁLLINGER, É.; TÓTH, M. Sgenotyping of old apple cultivars from the Carpathian basin: methodological, breeding and evolutionary aspects. Tree Genetics \& Genomes, v. 7, n. 6, p. 1135-1145, 2011. 
DOI: https://doi.org/10.1007/s11295-0110401-7.

HEO, S.; KWON, S.-I.; HWANG, J.-H.; SHIN, Y.-U.; KIM, M.-J.; PARK, B.J.; OH, S.-I.; OH, Y.-J.; KIM, D. Distribution of S-alleles among Korean apples by PCR and cross-pollination. Korean Journal of Horticultural Science and Technology, v. 30, n. 6, p. 757763, 2012. DOI: https://doi.org/10.7235/ hort.2012.12215.

KITAHARA, K.; MATSUMOTO, S. Sequence of the S10 cDNA from 'Mclntosh' apple and a PCR-digestion identification method. HortScience, v. 37, n. 1, p. 187-190, 2002. DOI: https://doi.org/10.21273/hortsci.37.1.187.

KVITSCHAL, M.V.; DENARDI, F.; SCHUH, F.S.; MANENTI, D.C. Identificação de polinizadoras para a cultivar de macieira Daiane. Revista Brasileira de Fruticultura, v. 35, n. 1, p. 9-14, 2013. DOI: https://doi.org/10.1590/ s0100-29452013000100002.

LI, W., YANG, Q., GU, Z., WU, C., MENG, D., YU, J., CHEN, Q., LI, Y., YUAN, H., WANG, D., LI, T. Molecular and genetic characterization of a self-compatible apple cultivar,'CAU-1'. Plant Science, v. 252, p. 162175, 2016. DOI: https://doi.org/10.1016/j. plantsci.2016.07.010.

MATSUMOTO, S. Apple pollination biology for stable and novel fruit production: Search system for apple cultivar combination showing incompatibility, semicompatibility, and full-compatibility based on the S-RNase allele database. International Journal of Agronomy, v. 2014, p. 1-9, 2014. DOI: https://doi.org/10.1155/2014/138271.

RAMALHO, M.A.P. Genética na agropecuária. 5. ed. Lavras, MG: UFLA, 2012. $566 p$.

SAPIR, G.; STERN, R.A.; SHAFIR, S.; GOLDWAY, M. Full compatibility is superior to semi-compatibility for fruit set in Japanese plum (Prunus salicina Lindl.) cultivars. Scientia Horticulturae, v. 116, n. 4, p. 394-398, 2008. DOI: https://doi.org/10.1016/j.scienta.2008.02.018.

SCHNEIDER, D.; STERN, R.A.; GOLDWAY, M. A comparison between semi- and fully compatible apple pollinators grown under suboptimal pollination conditions. HortScience, v. 40 , n. 5, p. 1280-1282, 2005. DOI: https:// doi.org/10.21273/hortsci.40.5.1280.

YAMANE, H.; TAO, R. Molecular basis of self-(in)compatibility and current status of S-genotyping in Rosaceous fruit trees. Journal of the Japanese Society for Horticultural Science, v. 78, n. 2, p. 137-157, 2009. DOI: https://doi.org/10.2503/jjshs1.78.137.
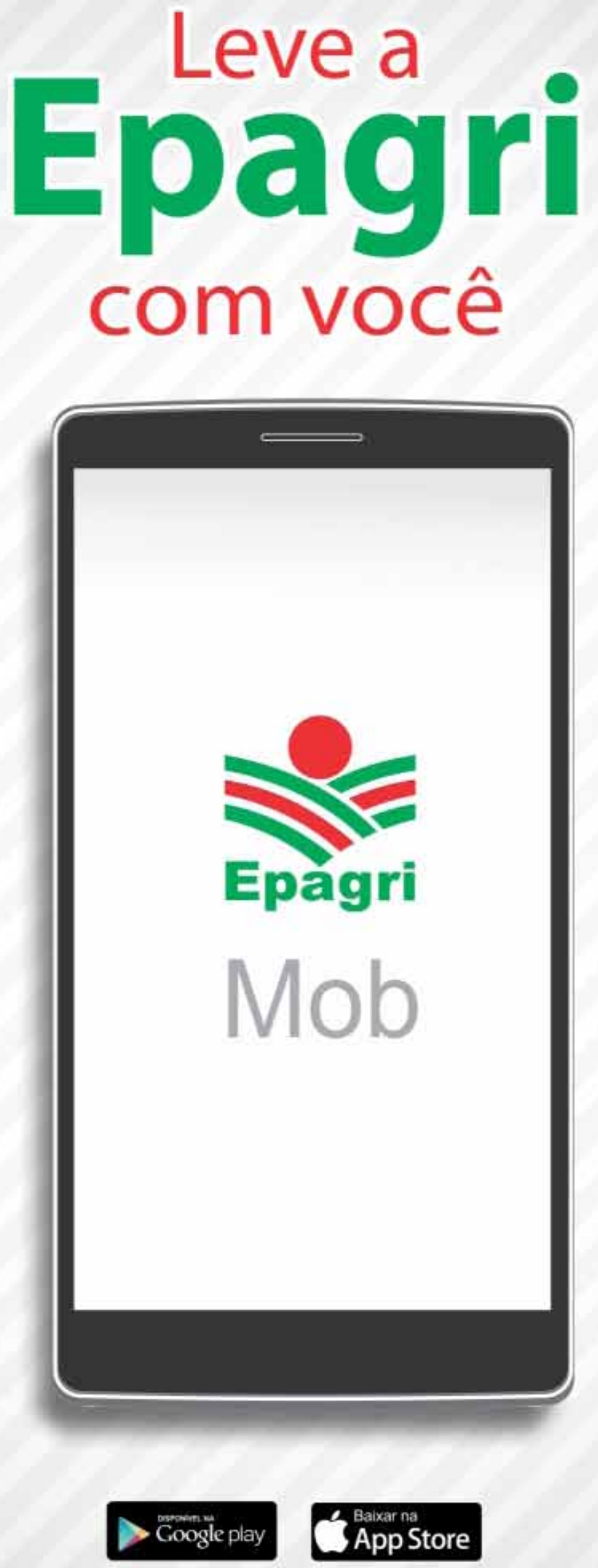